\title{
Implementasi Artificial Intelligence pada Charity Box Masjid dan Musholla sebagai Sistem Keamanan Berbasis RFID
}

\author{
Nurul pratiwi ${ }^{* 1}$, Ibnu Rasyid Munthe ${ }^{2}$, Muhammad Halmi Dar ${ }^{3}$ \\ ${ }^{123}$ Universitas Labuhan Batu, Rantau Prapat, Indonesia \\ Email: nurulpratiwi201788@gmail.com ${ }^{* 1}$, ibnurasyidmunthe@gmail.com²,
}

\begin{abstract}
Abstrak
Tingginya angka kriminalitas di Indonesia telah berdampak buruk dan merugikan masyarakat, sehingga berbagai upaya telah dilakukan untuk meningkatkan kesadaran dan keamanan di masyarakat. Pencurian kotak amal adalah target kejahatan bagi penjahat. Untuk itu perlu diambil langkah tegas dalam hal kewaspadaan dan keamanan agar tindak pidana pencurian kotak amal dapat dihindari. Salah satu langkah untuk meningkatkan kesadaran dan keamanan adalah dengan menerapkan konsep keamanan pada kotak amal. Dengan memanfaatkan beberapa sensor pendukung dan komponen pendukung pada kotak zakat maka sistem keamanan akan bekerja secara otomatis, sehingga jika terjadi pencurian kotak zakat maka sistem akan memberikan notifikasi notifikasi SMS kepada pihak pengelola masjid. Penelitian ini difokuskan pada masalah fasilitas keamanan dan pengawasan kotak amal di masjid atau mushalla. Menggunakan sistem ini akan mengurangi resiko pencurian kotak amal di masjid dan mushalla, karena selain dilengkapi dengan alarm dan SMS gateway, sistem ini juga dilengkapi dengan RFID sehingga akses membuka kotak amal bisa lebih aman. Bentuk sistem ini bekerja jika kotak amal diangkat atau dibongkar secara paksa, sistem akan memberikan notifikasi berupa alarm dan SMS, sehingga tindak pidana pencurian kotak amal dapat lebih diwaspadai.
\end{abstract}

Kata kunci : Arduino;RFID; HC-SR05; Sensor

\begin{abstract}
The high crime rate in Indonesia has had a bad and detrimental impact on the community, so various efforts have been made to increase awareness and security in the community. Charity box theft is a crime target for criminals. For this reason, it is necessary to take firm steps in terms of vigilance and security so that the crime of theft of charity boxes can be avoided. One of the steps to increase awareness and security is to apply the concept of security to charity boxes. By utilizing several supporting sensors and supporting components in the zakat box, the security system will work automatically, so that if a zakat box is stolen, the system will provide SMS notification notifications to the mosque manager. This research is focused on the problem of security facilities and supervision of charity boxes in mosques or mushalla. Using this system will reduce the risk of theft of charity boxes in mosques and prayer rooms, because in addition to being equipped with an alarm and SMS gateway, this system is also equipped with RFID so that access to open charity boxes can be safer. This form of system works if the charity box is lifted or unloaded forcibly, the system will provide notifications in the form of alarms and SMS, so that criminal acts of theft of charity boxes can be more vigilant.
\end{abstract}

\section{PENDAHULUAN}

Kejahatan merupakan suatu bentuk penyimpangan perilaku yang terjadi dalam kehidupan bermasyarakat, yang akan menjadi ancaman bagi norma-norma sosial masyarakat. Salah satu akibat dari suatu kejahatan atau tindak pidana adalah dapat mengganggu ketertiban umum dan keamanan sosial. Salah satu jenis kejahatan yang sering terjadi adalah kejahatan terhadap harta benda yaitu pencurian kotak amal. Kotak amal merupakan salah satu media yang digunakan untuk mengumpulkan sedekah dari masyarakat. Pada umumnya keamanan kotak amal sangat lemah karena hanya dilengkapi dengan gembok yang relatif mudah dibobol dan dicuri. (NI Qalbi dkk, 2020) 
Untuk itu keamanan kotak amal dirasa perlu ditingkatkan mengingat tingginya angka kriminalitas pencurian kotak amal di Indonesia, tidak sedikit pihak yang mengalami kerugian yang diakibatkan oleh pelaku kejahatan tersebut. Faktor ekonomi menjadi salah satu alasan pelaku berani melakukan kejahatan (Agus S, 2015).

Hal ini harus menjadi perhatian penting agar pencurian kotak amal di masjid atau musholla dapat dihindari. Sehingga berbagai upaya telah dilakukan untuk mengurangi risiko pencurian kotak amal di masjid dan di musholla. Salah satu langkah atau cara yang dapat dilakukan adalah dengan memiliki sistem keamanan pada kotak amal di masjid atau musholla. Pengenalan sistem keamanan kotak amal merupakan langkah awal untuk mengurangi risiko pencurian kotak amal. Konsep dari sistem keamanan kotak zakat ini adalah dengan mengimplementasikan beberapa sensor pendukung, sehingga jika terjadi pencurian kotak zakat maka sistem akan memberikan notifikasi berupa alarm dan notifikasi notifikasi SMS kepada pengurus masjid. Penelitian ini difokuskan pada masalah fasilitas keamanan dan pengawasan kotak zakat di masjid atau musholla.

Dengan menggunakan sistem ini akan mengurangi resiko pencurian kotak amal di masjid dan musholla, karena selain dilengkapi dengan alarm dan SMS gateway, sistem ini juga dilengkapi dengan RFID sehingga akses membuka kotak amal bisa lebih aman. Bentuk sistem ini bekerja jika kotak amal diangkat atau dibongkar secara paksa, sistem akan memberikan notifikasi berupa alarm dan SMS, sehingga tindak pidana pencurian kotak amal dapat lebih diwaspadai.

\subsection{Konsep Dasar Sistem}

\section{TINJAUAN LITERATUR}

Sistem adalah suatu jaringan dari prosedur-prosedur yang saling berhubungan dan secara bersamasama melakukan suatu kegiatan untuk menyelesaikan suatu tujuan tertentu. Sistem pada umumnya memiliki input yang dibutuhkan untuk diolah dan akan menghasilkan output berupa informasi. (Prof. Dr. Jogiyanto HM, MBA, Akt. Sistem Informasi Pendekatan Terstruktur Teori dan Praktek Aplikasi Bisnis. 2009 : 1).

\subsection{Sensor ultrasonik}

Sensor ultrasonik adalah sensor yang bekerja berdasarkan prinsip pemantulan gelombang suara dan digunakan untuk mendeteksi keberadaan suatu benda atau benda tertentu di depan frekuensi kerja pada daerah di atas gelombang suara dari $20 \mathrm{kHz}$ sampai $2 \mathrm{MHz}$ (B.Arasada dan B. Suprianto, 2017). Sensor ultrasonik terdiri dari dua unit yaitu unit pemancar dan unit penerima, struktur unit pemancar dan unit penerima. Sangat sederhana ada kristal piezoelektrik yang dihubungkan dengan jangkar mekanik dan hanya dihubungkan dengan diafragma getar tegangan bolak-balik yang memiliki frekuensi kerja $20 \mathrm{kHz}$ sampai $2 \mathrm{MHz}$ (B.Arasada dan B Suprianto, 2017).

Struktur atom kristal piezoelektrik menyebabkannya berkontraksi untuk mengembang atau menyusut, polaritas dari tegangan yang diberikan dan ini disebut efek piezoelektrik dalam sensor ultrasonik. Pemantulan gelombang ultrasonik terjadi ketika ada objek tertentu dan pantulan gelombang ultrasonik akan diterima kembali oleh unit sensor penerima. Selanjutnya unit sensor penerima akan menyebabkan diafragma getar bergetar dan efek piezoelektrik menghasilkan tegangan bolak-balik dengan frekuensi yang sama. Untuk lebih jelas mengenai prinsip kerja dari sensor ultrasonik, dapat dilihat prinsip kerja dari sensor ultrasonik pada Gambar 1 di bawah ini:

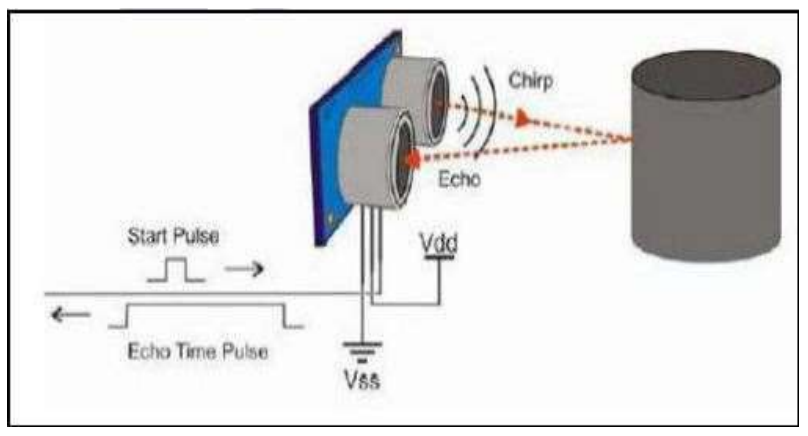

Gambar 1. Cara Kerja Sensor Ultrasonik 


\subsection{SMS Gateway}

SMS gateway adalah perangkat yang menawarkan layanan transit SMS, mengubah pesan ke jaringan seluler dari media lain, atau sebaliknya, sehingga memungkinkan pengiriman atau penerimaan pesan SMS dengan atau tanpa menggunakan ponsel. (E. Permana dan R. Hidayat, 2017)

Sebuah sistem SMS Gateway, umumnya terdiri dari komponen perangkat keras (server/komputer yang dilengkapi dengan perangkat jaringan) dan perangkat lunak (aplikasi yang digunakan untuk pemrosesan pesan). Dan untuk sistem yang besar umumnya menggunakan database untuk penyimpanan datanya.

\subsection{Arduino Uno}

Arduino Uno adalah papan mikrokontroler yang terdiri dari ATmega328. Arduino Uno memiliki 14 pin input/output digital (6 diantaranya dapat digunakan sebagai output PWM), 6 input analog, osilator Crystal $16 \mathrm{MHz}$, koneksi USB, colokan listrik, header ICSP dan tombol reset. Arduino Uno berisi semua yang Anda butuhkan untuk mendukung mikrokontroler, mudah untuk menghubungkannya ke komputer dengan kabel USB atau memasoknya dengan adaptor AC ke DC atau menggunakan baterai untuk memulai. (Ruri dan Surmayanti, 2016).

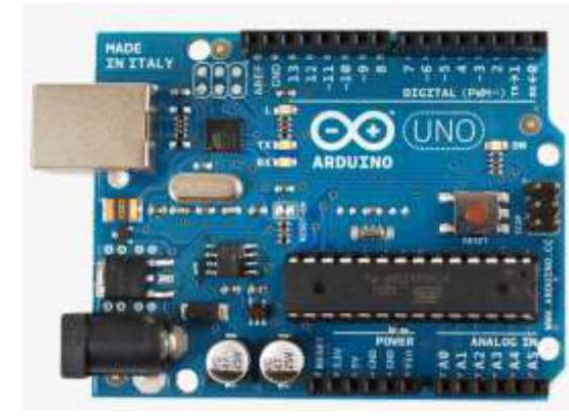

Gambar 2. Bentuk Fisik Arduino Uno

\subsection{Identifikasi Frekuensi Radio (RFID)}

Radio Frequency Identification (RFID) adalah teknologi yang memanfaatkan frekuensi radio untuk identifikasi otomatis dengan memanfaatkan barcode atau kartu magnetik untuk pengambilan data. Proses identifikasi dengan RFID memanfaatkan gelombang elektromagnetik oleh karena dalam proses identifikasi dengan RFID membutuhkan dua perangkat yaitu perangkat tag dan reader. (NI Qalbi dkk, 2020).

\section{METODE PENELITIAN}

Kerangka kerja ini merepresentasikan langkah-langkah yang akan dilakukan untuk memecahkan masalah yang akan dibahas, seperti terlihat pada Gambar 3:

\begin{tabular}{l}
\hline Tentukan Ruang Lingkup Masalah \\
$\downarrow \downarrow$ \\
\hline Studi Sastra \\
$\downarrow \downarrow$ \\
\hline Analisa sistem \\
$\downarrow$ \\
\hline Rancangan \\
\hline Perencanak Sistem \\
\hline Pembuatat Sistem \\
\hline Ujisistem \\
$\downarrow$ \\
\hline Penerapan \\
$\downarrow$ \\
\hline Gambar 3 Metodologi Penelitian
\end{tabular}


Berdasarkan Gambar di atas, ada langkah-langkah yang harus dilakukan dalam penelitian.

\subsection{Mendefinisikan Ruang Lingkup Masalah}

Masalah yang akan menjadi objek penelitian adalah bagaimana penerapan sistem kecerdasan buatan pada kotak zakat masjid dan musholla sehingga keamanan kotak zakat dapat meningkat, untuk menghindari resiko atau tindak kriminal pencurian kotak zakat.

\subsection{Mempelajari Sastra}

Studi literatur bertujuan untuk memudahkan proses penelitian. Kemudian literatur yang diteliti dipilih untuk menentukan literatur mana yang akan digunakan dalam penelitian. Literatur yang digunakan sebagai bahan referensi dalam penelitian ini adalah dari jurnal ilmiah internasional, modul pembelajaran dan buku tentang Sensor Ultrasonik, RFID, Arduino, Magnetic Door dan SMS Gateway. Literatur ini akan menjadi pedoman untuk melakukan penelitian guna memudahkan proses penelitian.

\subsection{Analisa sistem}

Tahap analisis sistem bertujuan untuk menganalisis segala sesuatu yang berhubungan dengan perancangan dan pembuatan sistem keamanan kotak zakat masjid dan musholla. Hal-hal yang dianalisis adalah sebagai berikut:

a. Penggunaan sensor ultrasonik dan RFID sebagai input;

b. Hardware dan Software yang digunakan dalam pembuatan sistem.

\subsection{Rancangan}

Tahap desain bertujuan untuk merancang sistem yang akan dibuat. Kemudian elemen-elemen yang terkandung akan ditentukan dan elemen-elemen tersebut akan dituangkan ke dalam flowchart. Bagan alir tersebut merupakan acuan alur dalam membuat sistem pengamanan kotak zakat masjid dan musholla.

\subsection{Perencanaan sistem}

Tahap perancangan sistem bertujuan untuk merancang sistem yang akan dibuat, seperti:

a. Desain Sistem Keamanan;

b. Desain sirkuit elektronik;

c. Desain program.

\subsection{Pembuatan Sistem}

Pada tahap ini yang akan dibuat adalah :

a. Membuat Charity Box dari kaca dan aluminium. dengan ukuran $30 \mathrm{~cm}$ x $30 \mathrm{~cm}$;

b. Pembuatan Sistem Kontrol.

\subsection{Pengujian Sistem}

Pada tahap pengujian sistem yang akan diuji adalah: Sistem keamanan kotak amal yang akan terintegrasi dengan RFID, sensor ultrasonik dan Modul GSM dan output berupa notifikasi berupa suara (alarm). Arduino sebagai perangkat lunak untuk pemrograman dengan bantuan alat downloader yang digunakan untuk memuat file program ke dalam mikrokontroler Arduino. Setiap modul elektronik akan diuji sehingga akan diketahui apakah modul tersebut berfungsi dengan baik atau tidak.

\subsection{Penerapan}

Pada tahap implementasi ini akan diimplementasikan perangkat seperti sensor ultrasonik dan RFID agar sistem dapat membaca dan mengolah data yang akan dikirimkan ke sistem kontrol dan akan memberikan informasi berupa notifikasi jika terjadi pencurian.

\subsection{Hasil Pengujian}

Pada tahap pengujian hasil akan dilakukan pengujian apakah data yang diperoleh dari alat input dapat diolah dengan baik sehingga menghasilkan output yang sesuai. Yang diuji pada tahap ini adalah:

1. Sensor ultrasonik;

2. RFID

3. Modul GSM (Berfungsi untuk memberikan informasi pesan) 


\subsection{Desain Sistem Umum}

\section{HASIL DAN PEMBAHASAN}

Secara umum bentuk sistem keamanan pada kotak amal ini dapat digambarkan dengan menggunakan Diagram Konteks dan Diagram Alir Data.

\subsection{Diagram konteks}

Dalam penelitian ini Diagram Konteks akan digunakan untuk mempermudah proses analisa sistem yang dirancang secara keseluruhan. Diagram konteks sistem dapat dilihat pada Gambar 4.

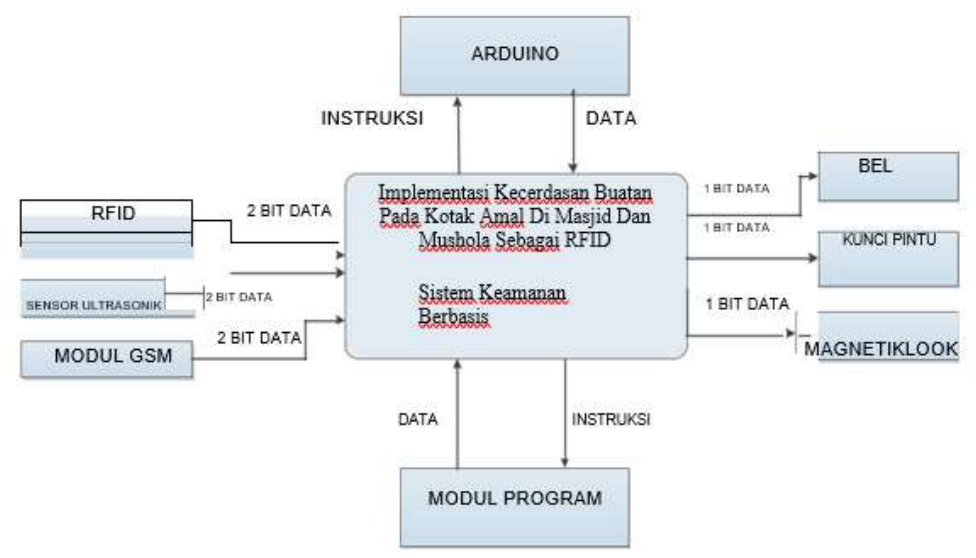

Gambar 4. Diagram Konteks 


\subsection{Prinsip Kerja Sistem}

Sistem keamanan kotak amal ini akan bekerja sesuai petunjuk berupa input data dari sensor Ultrasonic, RFID dan Modul GSM. Sensor ultrasonik berfungsi untuk mendeteksi jarak antara kotak amal dengan lantai tempat kotak amal diletakkan, sedangkan RFID berfungsi sebagai kunci pengaman ganda untuk membuka kotak amal. Sehingga apabila kotak amal tersebut dicuri atau dikeluarkan dengan sengaja diluar jarak aman atau $>75 \mathrm{~cm}$ maka alarm akan berbunyi sebagai peringatan dan Modul GSM akan mengirimkan pemberitahuan berupa pesan kepada pengelola masjid atau musholla bahwa telah terjadi pencurian kotak amal.

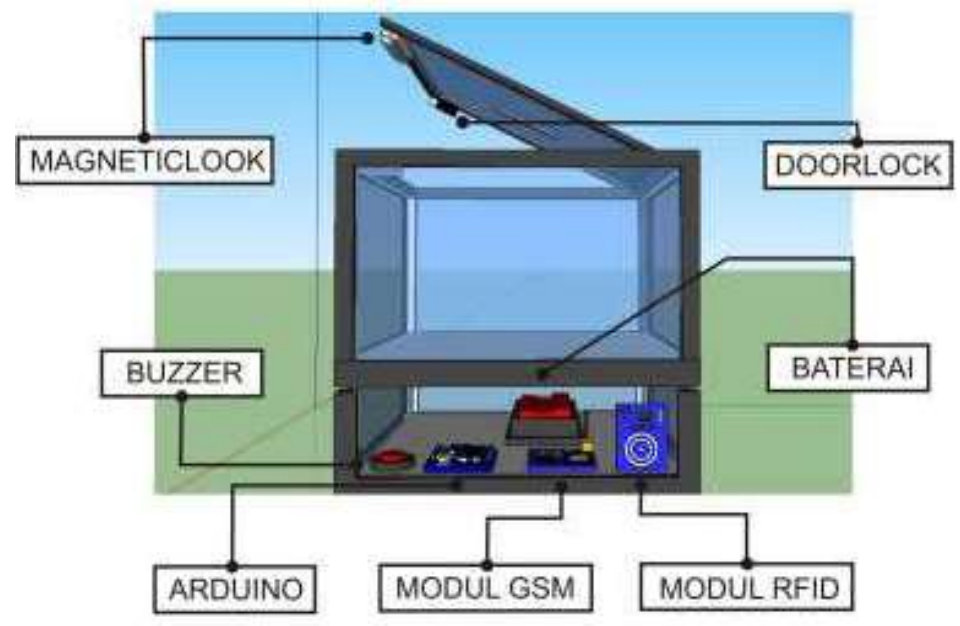

Gambar 5 Alat Desain

Pada Gambar 6 diatas merupakan bentuk fisik atau alat perancangan yang terdiri dari beberapa komponen yaitu : Arduino yang berfungsi sebagai pusat pengolahan data, Modul GSM berfungsi sebagai media komunikasi yang mengirimkan informasi berupa SMS, RFID berfungsi sebagai input media pengunci kotak amal, Battery berfungsi sebagai penyuplai tegangan arus rangkaian elektronik, Buzzer yang berfungsi sebagai alat keluaran berupa alarm, Doorlock, dan Magneticlock yang berfungsi sebagai pengunci kotak amal. Dengan komponen ini sistem akan dapat bekerja secara otomatis.

\subsection{Pengujian Sistem}

Sistem akan aktif ketika mendapat tegangan dari baterai Lippo dengan tegangan 12,4 Volt $2200 \mathrm{mAh}$. Jika sistem telah menerima tegangan/arus listrik, maka sensor dan komponen di kotak amal sistem keamanan akan mulai bekerja dan akan memberikan masukan.

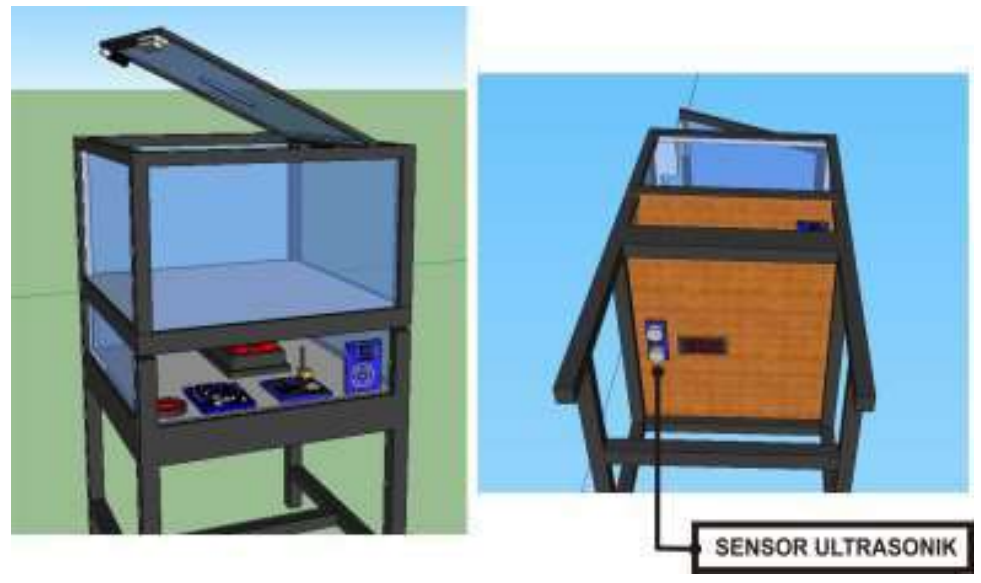

Gambar 6. Tampilan Kotak Amal yang Dilengkapi dengan Sensor dan Komponen Elektronik 
Pada Gambar 6 terlihat bagian bawah kotak amal, terdapat sensor ultrasonik yang berfungsi untuk mengetahui jarak kotak amal dari lantai. Jadi ketika kotak amal diangkat, sensor akan mendeteksi jarak antara kotak amal dengan lantai.

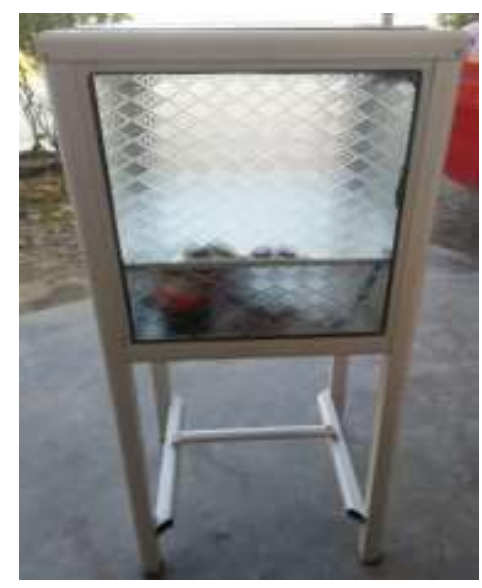

Gambar 7. Bentuk Fisik Sistem Pengamanan Kotak Amal Masjid dan Mushola

Gambar 7. diatas merupakan bentuk sistem pengamanan kotak zakat masjid dan musholla, jarak kotak zakat dengan lantai $75 \mathrm{~cm}$. masjid secara otomatis.

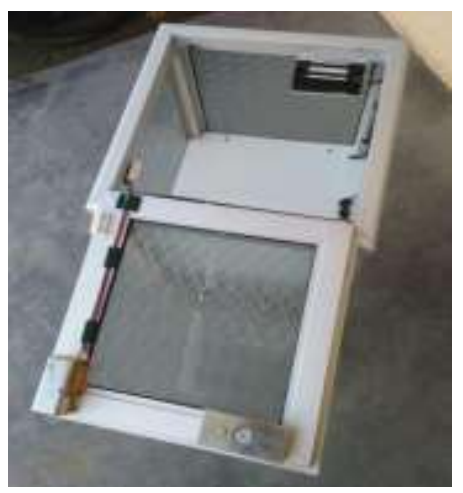

Gambar 8. Penggunaan Doorlock dan Magneticlock dalam Sistem Keamanan Charity Box

Pada gambar 8 terlihat Doorlock dan Magneticlock yang berfungsi untuk mengunci kotak amal secara otomatis. Sehingga dengan doorlock dan magneticklock ini, kotak amal dapat terkunci dengan kuat dan aman.

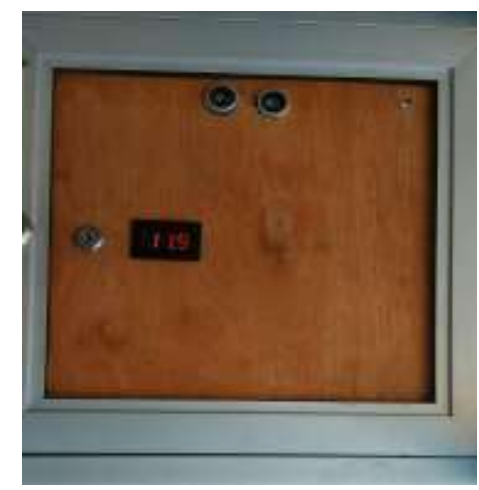

Gambar 9. Menampilkan indikator baterai pada Sistem Keamanan Charity Box 
Pada bagian bawah kotak amal selain dilengkapi dengan sensor ultrasonik juga dilengkapi dengan tampilan indikator baterai indikator baterai berfungsi sebagai media informasi untuk menginformasikan kondurna daya baterai.

\section{KESIMPULAN}

Setelah dilakukan pengujian sistem, didapatkan bahwa semua komponen elektronik dan sensor dapat bekerja dengan baik, sehingga sistem dapat bekerja dengan baik. Dengan menggunakan Modul GSM akan memudahkan pengurus untuk mendapatkan informasi secara langsung mengenai perampokan kotak amal tersebut. Untuk sistem penguncian kotak zakat menggunakan RFID, maka dengan penggunaan RFID ini akses unlocking kotak zakat dapat lebih aman dibandingkan dengan kunci manual. Dengan dibangunnya sistem keamanan ini bagi masyarakat dan dapat mengurangi resiko perampokan zakat, sehingga perampokan kotak zakat di masjid dan musholla dapat dihindari.

\section{DAFTAR PUSTAKA}

[1] Eka permana, rh (oktober 2017). Rancang bangun sistem keamanan rumah berbasis sms gateway menggunakan mikrokontroler. Jurnal teknologi informasi dan komunikasi, stmik subang.

[2] Nurul istiqamah qalbi, dkk. (april 2020). Rancang bangun intelligent chemical box sebagai solusi inefisiensi distribusi kotak karakter di masjid. Jurnal elektrik media, vol. 17, no. 2.

[3] Suharsoyo, a. (maret 2015). Karakter pencegahan tindakan pidana. Yurisprudensi vol. 5 nomor 1.

[4] Suprianto, ba (2017). Aplikasi sensor ultrasonik untuk deteksi posisi jarak dalam ruangan menggunakan arduino uno. Jurnal teknik elektro jilid 06 nomor 02, 137 - 145.

[5] Jogiyanto, hm. 1992. Esensi elektronika. Jakarta: pt. Elex media computindo

[6] Kusumadewi, sri (2003), "kecerdasan buatan (teknik dan penerapannya)". Yogyakarta: graha ilmu. [7] Zain, rh \& surmayanti, 2016. Merancang sistem buka tutup pintu air otomatis di muara sungai /Reservoir menggunakan sensor infra merah dan photo diode dengan tampilan lcd berbasis arduino uno atmega-328.jurnal teknologi informasi \& pendidikan, 9 (1), hlm. 67-72.

[8] Andrianto, heri. 2008. Pemrograman mikrokontroler atmega avr 16. Bandung: penerbit informatika

[9] Sutojo, t, mulyanto, edi, suhartono, vincent, dr. (2011), "kecerdasan buatan".

[10] Eko harli, af (2017). Perancangan dan Implementasi Teknologi SMS Gateway Mesin Biometrik Terintegrasi Dalam Sistem Informasi Akademik. Jurnal Teknik Informatika dan Teknologi Pendidikan, Volume 01 Nomor 02 ,.

[11] Hendi handian rachmat, ga (2014). Penggunaan sistem rfid sebagai penghalang akses ruangan. Jurnal elkomika, no 1, vol 2.

[12] Muhammad akil, am (2020). Perancangan kotak karakter mesjid tanpa sentuh dalam upaya menghadapi order baru di tempat ibadah mediatik jurnal: jurnal teknik informatika dan media pendidikan komputer, vol.2 no.2.

[13] Teguh kurniawan, t. (2019). Pembuatan sistem filter dan monitor air untuk reservoir berbasis mikrokontroler atmega328. Jurnal geografi capita selekta, 44 - 55). 